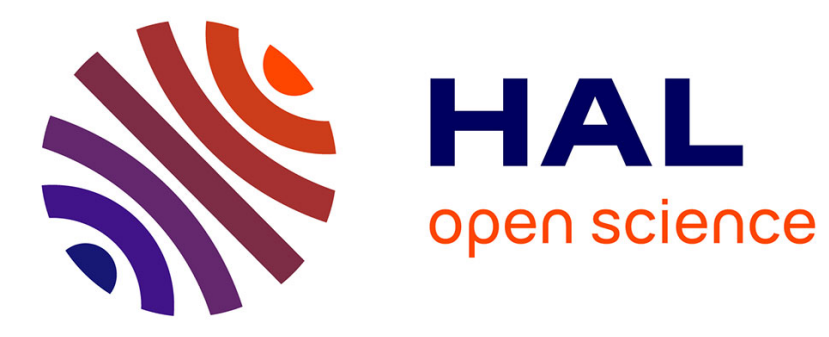

\title{
Orages: A dedicated sensor for detection, localisation and fine analysis of lightning flashes from space
}

\author{
Anne Bondiou-Clergerie, Philippe Lalande, Frank Roux
}

\section{To cite this version:}

Anne Bondiou-Clergerie, Philippe Lalande, Frank Roux. Orages: A dedicated sensor for detection, localisation and fine analysis of lightning flashes from space. 54th International Astronautical Congress of the International Astronautical Federation, the International Academy of Astronautics, and the International Institute of Space Law, Sep 2003, Brême, Germany. pp.245-254, 10.2514/6.IAC-03B.3.06 . hal-00138891

\section{HAL Id: hal-00138891 https://hal.science/hal-00138891}

Submitted on 9 Sep 2021

HAL is a multi-disciplinary open access archive for the deposit and dissemination of scientific research documents, whether they are published or not. The documents may come from teaching and research institutions in France or abroad, or from public or private research centers.
L'archive ouverte pluridisciplinaire HAL, est destinée au dépôt et à la diffusion de documents scientifiques de niveau recherche, publiés ou non, émanant des établissements d'enseignement et de recherche français ou étrangers, des laboratoires publics ou privés. 


\title{
"ORAGES" : A DEDICATED SENSOR FOR DETECTION, LOCALIZATION AND FINE ANALYSIS OF LIGHTNING FLASHES FROM SPACE
}

\author{
A. Bondiou-Clergerie ${ }^{1}$, P. Lalande ${ }^{2}$, F. Roux $^{3}$ \\ ${ }^{1}$ Onera, 29 Av. de la division Leclerc, 92322 Chatillon, France, bondiou@onera.fr \\ ${ }^{2}$ Onera, lalande@onera.fr \\ ${ }^{3}$ Laboratoire d'Aérologie, 14 Av. Edouard Belin, 31400 Toulouse, France, frank.roux@aero.obs-mip.fr
}

\begin{abstract}
According to mission parameters, spacebased lightning sensors enable detailed analysis of mesoscale convective systems and large scale atmospheric perturbations (e.g. intertropical convergence zone, monsoon regions, tropical cyclones) and / or statistical studies of the global parameters related to electrical activity on a large spatial and temporal scale. Measurement of spatial distribution and frequency of atmospheric discharges, correlated with meteorological satellites observations, gives the opportunity to have a more precise knowledge of convective systems, to identify the more active regions, to characterise their life cycle and to establish a geographical and seasonal climatology of thunderstorms. Additionally, the global analysis of the electrical activity of thunderstorms could be a diagnosis element of global warming or a quantitative basis for the compared evaluation of natural and anthropic production of nitrogen oxides. Within the CNES microsatellite program, the ORAGES mission was proposed in order to carry out lightning detection, localisation and characterisation based upon the interferometric analysis of their VHF radiation. The present paper describes the different components of the instrument (antenna network, receiver and data processing system) and presents an evaluation of its performances.
\end{abstract}

\section{INTRODUCTION}

Several systems have been developed to detect and locate lightning flashes from ground both for research and operational purposes. In order to investigate lightning activity on a global basis, NASA has developed space-based cameras to locate and detect lightning with storm scale resolution (10 to $15 \mathrm{~km}$ ). The Optical Transient Detector (OTD) was launched in April 1995 aboard the MicroLab-1 satellite at an altitude of $740 \mathrm{~km}$ and an inclination of $70^{\circ}$ with respect to the equator. The Lightning Imaging System (LIS) is one of the instruments aboard TRMM (Tropical Rainfall Measuring System) satellite launched in November 1997 at an altitude of $350 \mathrm{~km}$ and an inclination of $35^{\circ}$, designed to monitor and study tropical rainfall and the associated release of energy. OTD and LIS have provided detailed and comprehensive data on the geographical and seasonal distribution of lightning. In August 1997, the Los Alamos National Laboratory has launched the FORTE satellite (Fast On-Orbit Recording of Transient Events) dedicated to a comprehensive study of all kinds of electromagnetic emission in the range of 20 to $330 \mathrm{MHz}$. Although the FORTE instrument did not allow to locate precisely the detected RF sources, it has provided large amounts of data relative to lightning radiation.

The ORAGES project, selected in 1998 by the French space agency (CNES) for a preliminary phase study to validate the instrument concept, is a continuation of these studies. The main difference between OTD, LIS and ORAGES concerns the method used for lightning detection. OTD and LIS detect and locate the optical flashes associated with lightning at a wavelength of $777.65 \mathrm{~nm}$, while ORAGES - like FORTE - will use the VHF radiation. This is believed to obtain a better detection efficiency (>90\%), independently of day/night or ocean/continent background, to allow a large field of view (> $1000 \mathrm{~km} \times 1000 \mathrm{~km}$ ) with a possibility of detection up to the limb $(6400 \mathrm{~km} \times$ $6400 \mathrm{~km}$ ), and to provide of additional information on the lightning flashes. The main difference with FORTE is that localization of lightning will be possible using an interferometric technique for ORAGES.

\section{SCIENTIFIC OBJECTIVES}

ORAGES will provide a continuous observation of the lightning activity with analysis of the space and time distribution of lightning discharges. Onboard numerical analyses will provide complementary information as discrimination between intra-cloud and cloud-toground flashes, evaluation of the total lightning length, structure of the emitted electromagnetic radiation. The mission will then answer to the main following scientific objectives :

\section{Study of convective systems}

In a thundercloud, the emergence of disruptive electric fields results from electrification processes closely related to cloud dynamics and hydrometeors distribution. Hence, the rate of total lightning flashes and the ratio of cloud-to-ground discharges 
are strongly correlated with the updraft intensity (Lhermitte and Williams, 1983) and the liquid water content (Saunders et al, 1991) in the thundercloud. These correlations may give rise to quantitative relationships, relating flash rate to rainfall intensity (see for example Figure 1 and (Chèze and Sauvageot, 1997)). Results from the TRMM/LIS mission also points out the strong relationship between lightning activity, cloud dynamics and ice content. inferred from microwave brightness temperature. Furthermore, recent studies have shown how lightning data can complement microwave measurements (Toracinta nad Zipser, 2001, Toracinta et al, 2002). Detection of lightning is associated with the presence of supercooled liquid water mixed with graupels. This liquid water can also produce a microwave emission which biases the apparent brightness temperature. Hence, lightning detection could be used to correct for this effect and to improve rainfall estimation from microwave brightness temperature.
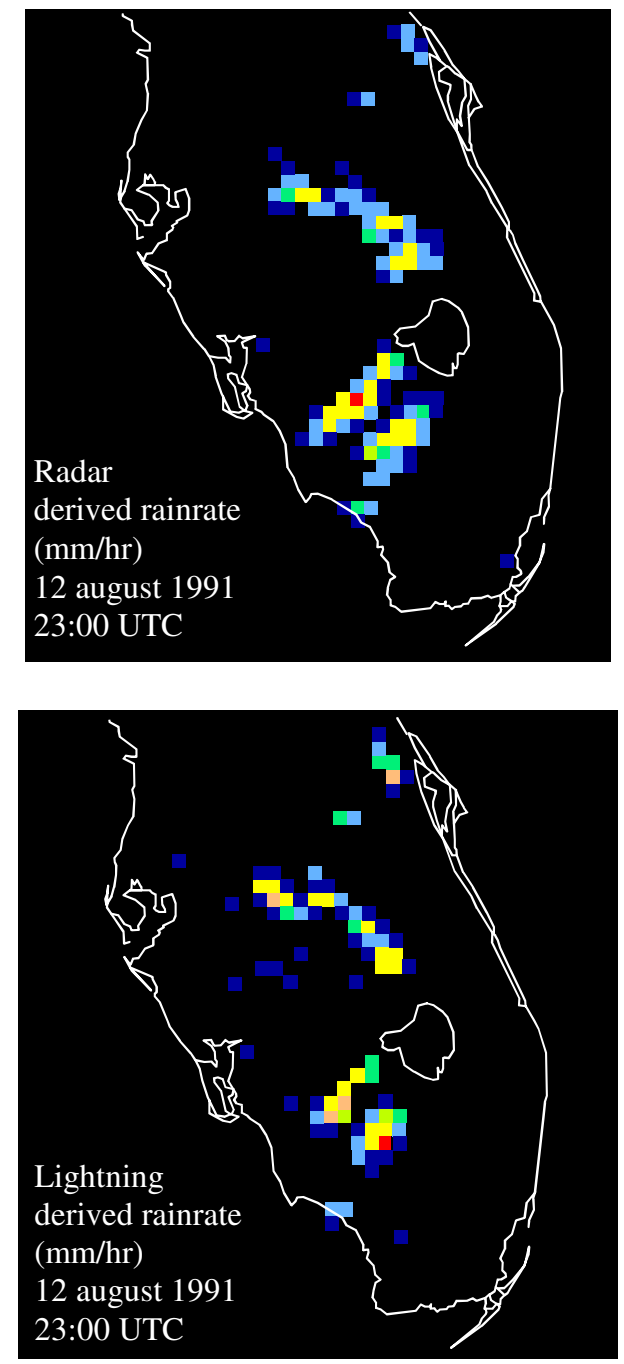

Figure 1 Comparison of ground precipitation retrieved from lightning activity

parameterization with ground precipitation retrieved from radar data (NASA document)
It is then expected than data provided by ORAGES on the intra-cloud and cloud-to-ground lightning activity within convective systems can be combined with that from ground-based and spaceborne meteorological observing devices, to investigate the processes involved in the evolution of convective systems, with investigation of the following themes:

- Classification of electrical activity as a function of cloud type (continental or oceanic, convective or stratiform, mesoscale organization, evolution, duration, ...) ;

- Deduction of relationships between electrical activity and rainfall intensity (provided by direct raingauges - or indirect - radars, radiometers, ... measurements).

- Specific analysis of lightning activity associated with perturbations of the tropical atmosphere (cyclogenesis, tropical and equatorial waves, intra-seasonal oscillation, monsoons, ...).

\section{Climatology}

In the last decade, numerous scientific studies have showed that year-to-year evolution of the global lightning activity may provide a sensitive measure of large-scale temperature variations associated with climate change frequency (Price, 1993, Williams, 1994). Indeed, climate simulations with doubled $\mathrm{CO}_{2}$ concentration suggest a $25 \%$ increase in global lightning. An important new finding is the strong correlation between global lightning and upper tropospheric water vapor (UTWV) which has a large impact on the green house effect (Price, 2000). Space borne measurements of lightning activity can therefore be used as complementary but sensitive data for monitoring and understanding of earth's climate changes.

Evaluation of $\mathrm{NO}_{\mathrm{X}}$ production by lightning Within the lightning channel, temperature becomes higher than $20000 \mathrm{~K}$, leading to the breakup of $\mathrm{N}_{2}$ and $\mathrm{O}_{2}$ molecules into nitrogen and oxygen atoms. During the cooling process, nitrous oxides $\mathrm{NO}_{\mathrm{X}}$ and other trace gases are produced. These nitrous oxides are involved in the production of tropospheric ozone, but the global contribution and the relative efficiency of different types of lightning flashes (intracloud versus cloud-to-ground) to produce $\mathrm{NO}_{\mathrm{X}}$ is not well known. The ORAGES mission enables statistical estimation of the number of flashes, and can provide an approximation for the lightning channel length (involved as a parameter in the calculation of the NOx amount produced within one flash) 
Analysis of the mechanisms of electromagnetic radiation emitted by lightning flashes

The FORTE mission has pointed out the existence of Trans-Ionospheric Pulse Pairs (TIPPs), which are pairs of intense VHF electromagnetic energy pulses, hardly detectable with ground systems . TIPPs are frequently associated with upper atmospheric discharges called "Sprites", "Jets" and "Elves", and with intense X- and gamma-ray energy bursts. There seems to be a correlation between TIPPs and peak VHF radiations from energetic discharges, but the available data are still sketchy. The ORAGES mission aims to investigate the space and time distribution of these pulses in order to understand their physical origin.

\section{GEOPHYSICAL PARAMETERS TO BE RETREIVED}

To be consistent with these scientific objectives, the ORAGES functions are the following:

- Detection, localization and time sampling of the VHF lightning emission, within a field of view of $1000 \mathrm{~km} \times 1000 \mathrm{~km}$, with a horizontal resolution is equal or better than $15 \mathrm{~km} \times 15 \mathrm{~km}$;

- Outside this region, localization of the most intense emissions up to the limb $(3200 \mathrm{~km}$ horizontally from the nadir) with a horizontal resolution equal or better than $150 \mathrm{~km} \times 150 \mathrm{~km}$;

- Reconstruction of lightning channels from the series of VHF lightning sources using spatial and temporal criteria;

- Evaluation of the total lightning length;

- Discrimination between intra-cloud and cloudto-ground flashes;

- Determination of the type of emission (lightning leader development, recoil streamers, TIPPs, ... ).

\section{MISSION PARAMETERS}

Through a low inclination on the equatorial plane $\left(20-25^{\circ}\right)$, measurements will be made with ORAGES at a relatively high repetitivity. ORAGES will be devoted to the observation of the intertropical zone $\left(\approx 25^{\circ} \mathrm{S}-25^{\circ} \mathrm{N}\right)$ where most convective activity occurs. The altitude of the orbit will be high enough $(750-850 \mathrm{~km})$ to allow a wide field of view, while permitting a reasonable horizontal resolution $(<15 \mathrm{~km})$. This mission is an experimental mission without plan for immediate operational follow-up. In order to study phenomena ranging from individual convective events to interannual variability, the duration of the mission should be at least 2 years. It is highly desirable that ORAGES be coordinated with meteorological satellites devoted to the observation of precipitating systems and their environments in the tropics.

\section{PAYLOAD DESCRIPTION}

\section{General principles from lightning detection through its VHF radiation}

Lightning discharges are always associated with a strong atmospheric electromagnetic signal with frequencies up to the GigaHertz. The VHF radiation is made of series of bursts of radiation associated to the different lightning phases. Each bursts of radiation can be associated with several radiative elements which can be located through two different techniques. The first one is based on a measurement of range difference, which implies to use a minimum of 4 stations separated by several tenths of kilometers. This method could only be applied if a constellation of satellites were to fly in Earth's orbit. The second method is based on a bearing measurement. The direction where the lightning radiation is coming from is determined by an interferometric network of antennae. The 2D location of the lightning emission is obtained by the intersection of the bearing measurement with the earth surface. This principle enables the design of an instrument compatible with the constraints of a microsatellite platform. For example, when two antennae are considered, the phase difference $\phi$ between them is given by the following expression (see Figure 2) :

$$
\phi=2 \pi \frac{D}{\lambda} \sin \theta \sin \varphi
$$

where $\mathrm{D}$ is the distance between the antennae and $\lambda$ the wavelength of the signal, $\varphi$ and $\theta$ the azimuth and site of the radiation source.

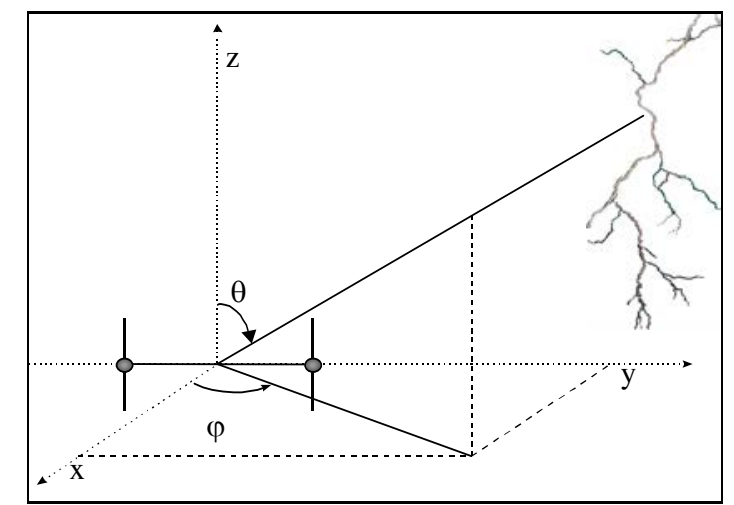

Figure 2: Principle of a bearing measurement with two antennae.

When more than two antennae and several baselines are considered, an unambiguous localization can be obtained. An example of lightning observations from ground stations using such a method is presented Figure 3. 


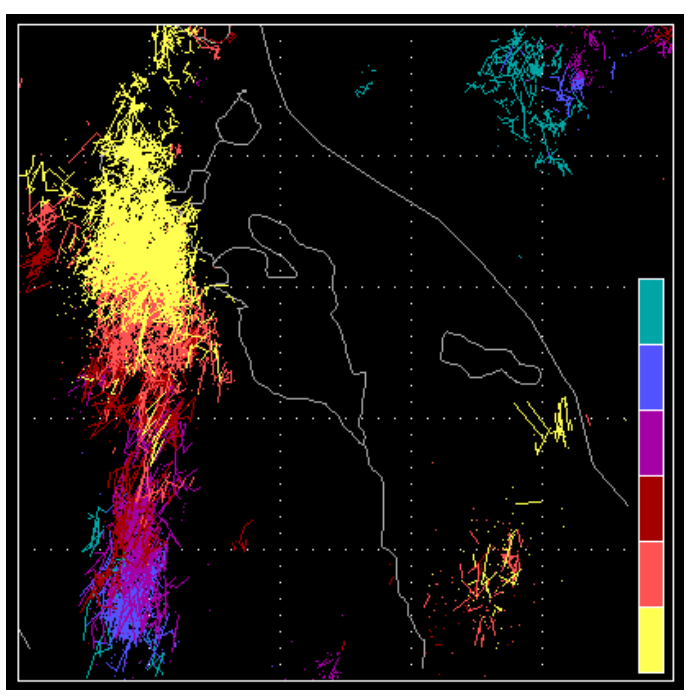

Figure 3 : Image of the electrical activity performed by two bearing stations based on interferometric measurements (ONERA/ITF). Thunderstorm of 08/14/92 de 19:00 à 20:00 GMT near the Kennedy Space center in Florida. The color scale is associated with time evolution of the storm activity: the blue-green and yellow colors refer to the earliest and latest flashes, respectively.

\section{Main features of the ORAGES instrument}

The scientific objectives of the mission prescribe a location error in the range $5-15 \mathrm{~km}$. This location error varies with the azimuth and site according to the antennae array geometry and to the phase combination algorithm; it is also directly proportional to the root mean square error on the phase measurement $\mathrm{d} \phi_{\mathrm{rms}}$ :

$$
d \phi_{r m s}=\sqrt{\frac{1}{\Delta f . \Delta t}} 10^{-\frac{S N R}{20}} .
$$

with $\Delta \mathrm{f}$ being the bandwidth, $\mathrm{t}$ the cumulated duration of the emission associated to the considered radiative element, and SNR the signal to noise ratio.

The intensity of lightning radiation in VHF is inversely proportional to frequency and it has been demonstrated that a central frequency around $120 \mathrm{MHz}$ is a good compromise leading to an acceptable SNR with a reasonable antenna size. The rise of the bandwidth $\Delta \mathrm{f}$, necessary to lower $\mathrm{d} \phi_{\mathrm{rms}}$ down to $2^{\circ}$, has been achieved through the design of a broadband system with a digital receiver; the cumulated emission duration $\Delta t$ is maximized through the signal digital processing. The digital receiver enables to select the wideband signals associated with lightning flashes amond anthropognenic noise: this method allows the use of a maximum fraction of the initial bandwidth.

The instrument is then made of three main subsystems (see Figure 4):

- The antenna array (see below)
- The analog HF head which performs the filtering and amplification functions

- The digital receiver including $\mathrm{AD}$ converters (40 Msamples/s) and real time processing DSP, including a triggering module that ensures the selection of the useful signal

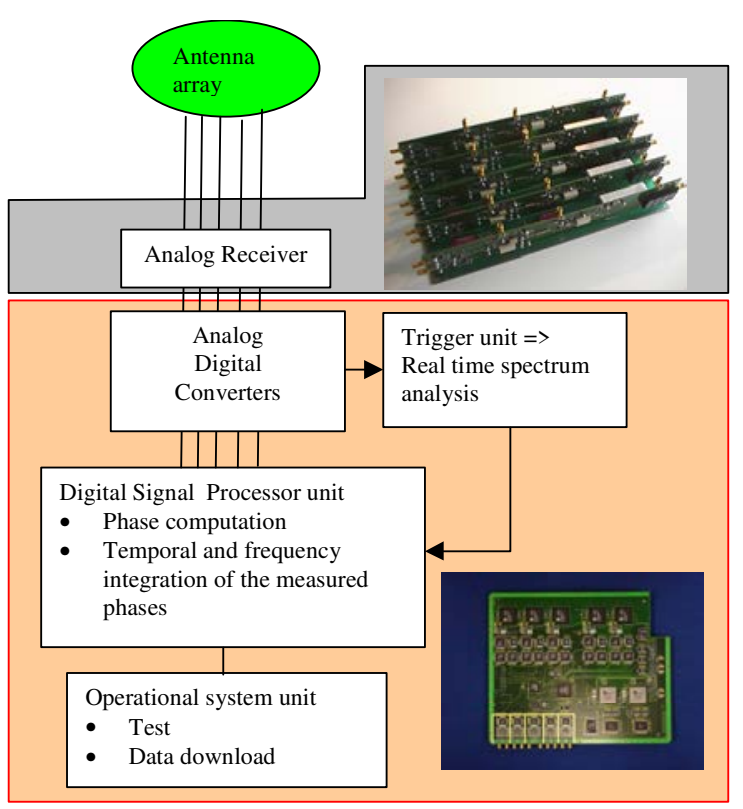

Figure 4: ORAGES instrument structure

The antennae network has been designed to ensure the required resolution with a minimum number of antennae and array size. It can be shown that the size of the detection pixel is the following :

$$
d_{p} \propto d \Phi_{r m s} H \frac{\lambda}{D} \frac{1}{\cos ^{4}\left(a \tan \left(\frac{r}{H}\right)\right)}
$$

with $\quad d_{p}$ : pixel size

$\mathrm{H}$ : satellite altitude

$\lambda$ : wavelength

$\mathrm{D}:$ array radius for a circular array

$\mathrm{r}$ : distance from the center of the footprint $(\mathrm{r}=0$ at nadir)

The calculations given by Figure 5 show that the choice of a circular array of $1.5 \mathrm{~m}$ radius with 5 antennae enables to reach a maximum pixel size lower that $12 \mathrm{~km}$ at the edge of the $500 \mathrm{~km}$ footprint (middle of the bandwidth).

It is also possible to extend the field of view up to the limb with a reduced resolution on the edges of the footprint (see Figure 6): this allows to reach a better detection efficiency useful for statistical studies of lightning activity 

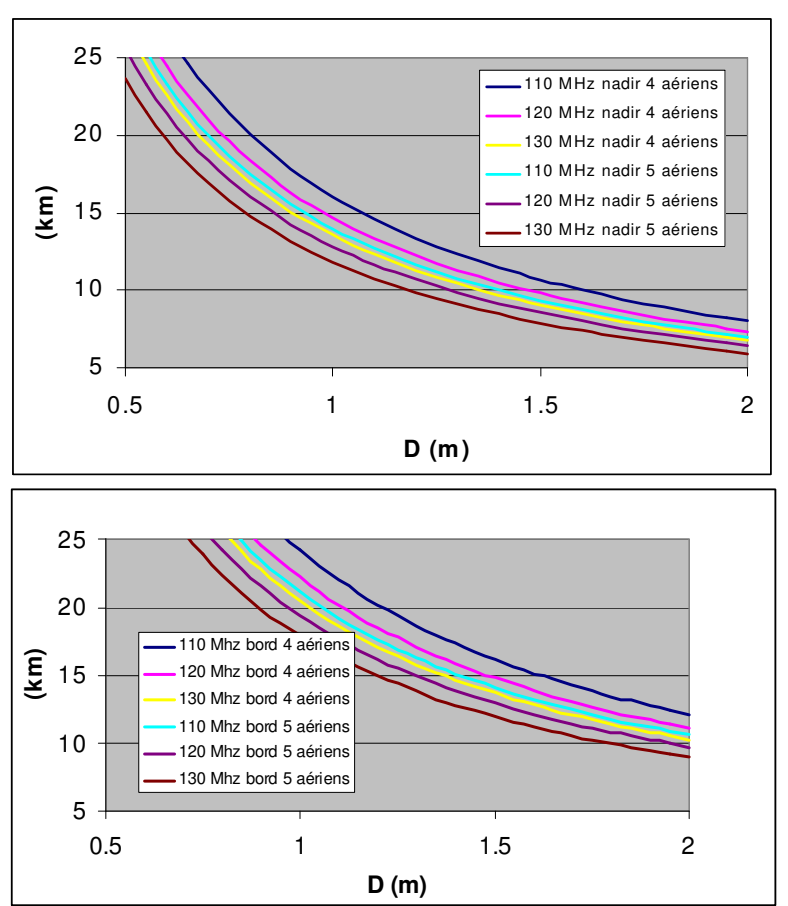

Figure 5: Calculation of the space resolution as a function of the radius $D$ of a circular array of antennae over the whole bandwidth (110-130 $\mathrm{MHz}$ ), for 4 or 5 antennae. The calculation is performed in the center ( $r=0$, top image) and at the edge of the footprint ( $r=500 \mathrm{~km}$, bottom image) for $d \phi_{r m s}=2^{\circ}$ and $H=700 \mathrm{~km}$

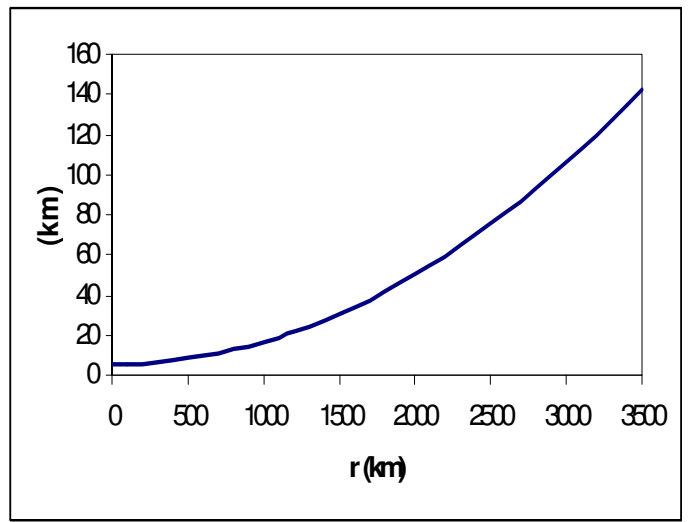

Figure 6 : Calculation of the space resolution as function of the distance from the center of the footprint in the case of an extended field of view (satellite altitude $H=740 \mathrm{~km}$; phase error $=2^{\circ}$; radius of antenna array $=2 \mathrm{~m}$ )

For the development of the scientific payload, a prototype of ORAGES has been designed and developed in 2001. It is based on a broad band VHF interferometer composed of a 5 antenna network with a center frequency of $120 \mathrm{MHz}$ and a diameter of 3. $\mathrm{m}$, an analog receiver and a numerical unit for real-time signal analysis which characteristics are listed in Table1. In October 2001, the prototype has been installed inside a balloon nacelle (Figure 7).

\begin{tabular}{|c|c|c|c|}
\hline & Weigth & Volume & Power \\
\hline Antenna array & $<6.5 \mathrm{~kg}$ & & - \\
\hline Analog receiver & $2.5 \mathrm{~kg}$ & $6.251 \mathrm{dm}^{3}$ & $15 \mathrm{~W}$ \\
\hline $\begin{array}{c}\text { Digital signal } \\
\text { processing unit }\end{array}$ & $4 \mathrm{~kg}$ & $4.21 \mathrm{dm}^{3}$ & $28 \mathrm{~W}$ \\
\hline
\end{tabular}

Table 1 : Characteristics of the ORAGES prototype.

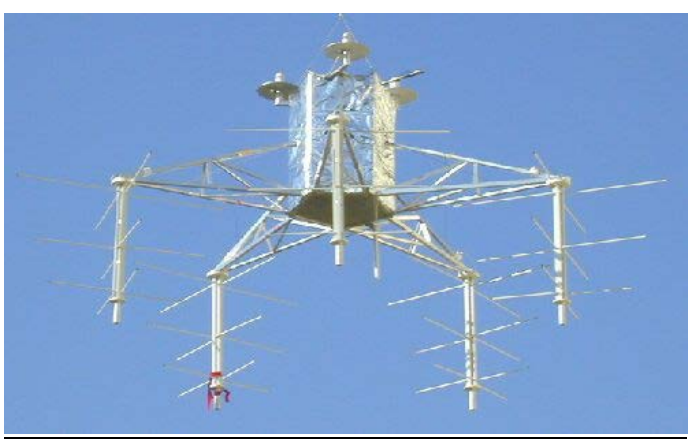

Figure 7 : The balloon nacelle of ORAGES with the 5-antenna network

One test-flight has been conducted and has permitted to validate the working order of the ORAGES scientific payload (antennae, analog receiver, real-time signal processing). Figure 8 shows a possible implementation of ORAGES on a microsatellite, with antennae slightly different from those used during the balloon-borne test flights.

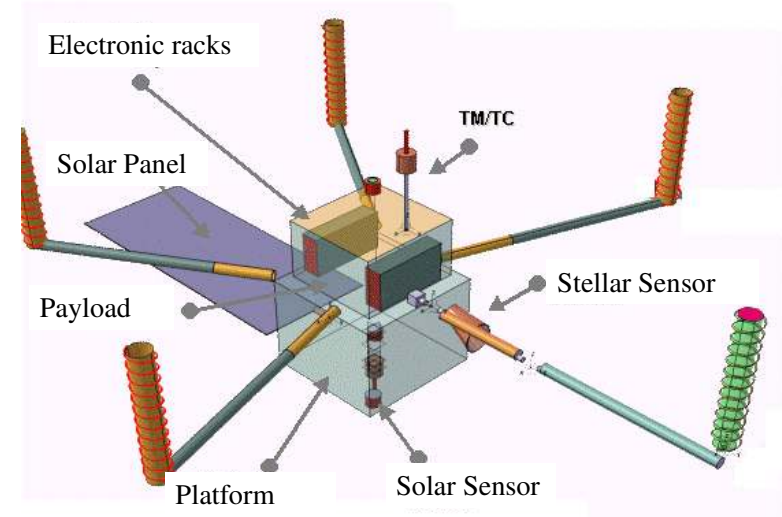

Figure 8: Implantation of ORAGES on a microsatellite platform

\section{EXPECTED SYSTEM PERFORMANCES}

Case of mesoscale convective systems

One of the main objectives of the ORAGES mission is the observation of mesoscale convective systems, lightning activity being used to characterise their life cycle. The ability of the ORAGES instrument to full fill this requirement 
has been simulated using the following assumptions:

- Simulation of a convective system : A typical mesoscale convective system is simulated with a recurrent daily development from $16 \mathrm{~h} 00 \mathrm{UT}$ to 19 h00 UT. During its lifetime, the lightning activity is simulated by three bi-exponential waveforms each one being shifted from another by 1 hour (Figure 9); this time shape simulates a typical life cycle of a thunderstorm. The flash rate reaches its maximum value of 125 flashes/min in $700 \mathrm{~s}$ and decreases to 10 flashes/min with a decay time of $2000 \mathrm{~s}$. The mean flash rate is 0.98 flash/s during the 3 hours of the lightning activity. The lightning activity is assumed to be uniformly distributed on a square surface of $111 \mathrm{~km} \mathrm{x} 111 \mathrm{~km}$, this parameters being consistent with the size of large convective fronts.

- Mission parameters : The inclination on the equatorial plane of the orbit is $25^{\circ}$. The altitude of the orbit is $740 \mathrm{~km}$.

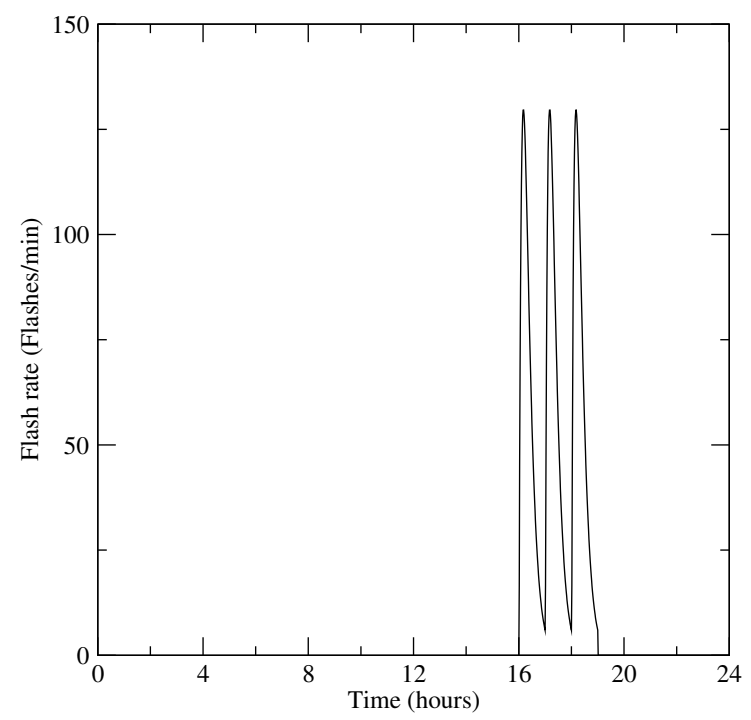

Figure 9 : Simulation of a typical flash rate of a storm of 3 hours of duration. The storm develops from $16 \mathrm{~h} 00 \mathrm{UT}$ to $19 \mathrm{~h} 00 \mathrm{UT}$.

In Figure 10 , the detected flash rate has been computed with the following assumptions :

- The simulated convective system is centred around $0^{\circ}$ of latitude and $0^{\circ}$ of longitude.

- The field of view of the ORAGES instrument is set to the limb (low spatial resolution mode). The radius of the observed area is $3200 \mathrm{~km}$.
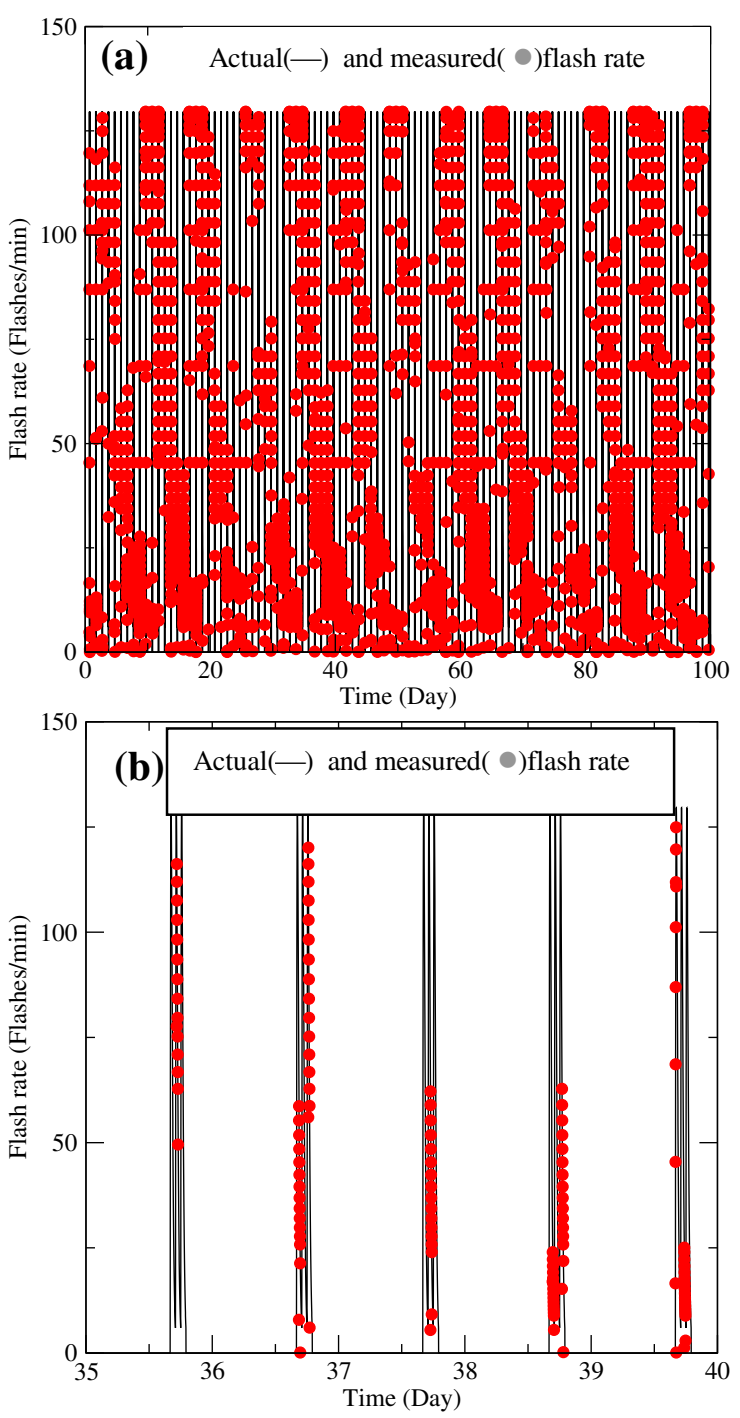

Figure 10: Flash rate measured by ORAGES for a typical storm at $0^{\circ}$ of latitude and $0^{\circ}$ of longitude with a field of view up to the limb.(a)100 days of observation; (b) 5 days of observation

This figure shows in black line the actual lightning activity in the convective area. The detected flash rate has been plotted in full red circles,. The figure shows that the ORAGES instrument can provide a good sampling of the lighting activity evolution on a daily basis, as the flash rate is measured twice a day during at least 12 minutes.

In Figure 11, the simulation has been performed with the same hypothesis that in Figure 10, except that the convective system is placed at $20^{\circ}$ of latitude. The figure shows that ORAGES has a 30 days of observation of the lightning activity which are followed by 20 days during which the convective system is out of the field of view of ORAGES. During observation periods, the time sampling of the flash rate is similar as the one of Figure 10. 


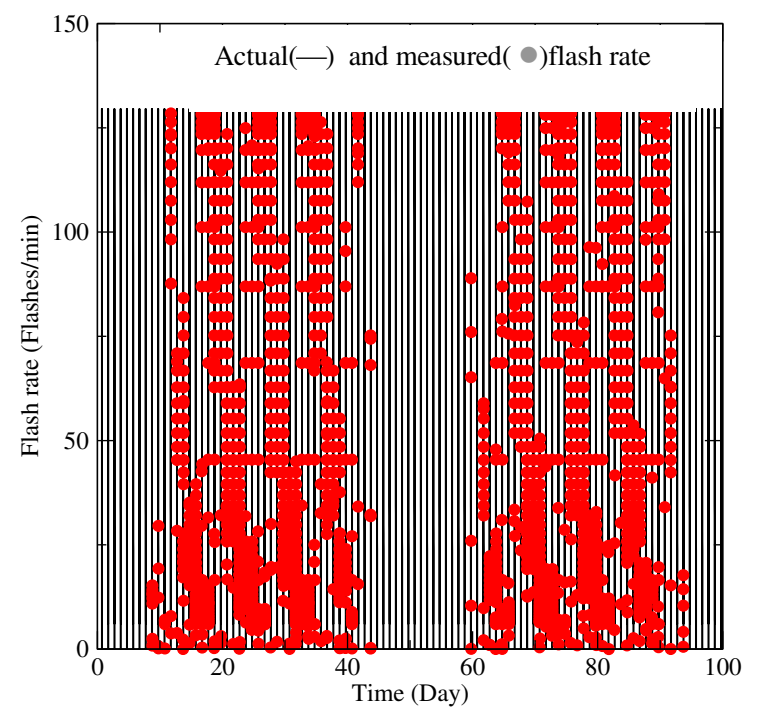

Figure 11: Flash rate measured by ORAGES for a typical storm at $20^{\circ}$ of latitude and $0^{\circ}$ of longitude with a field of view up to the limb.

The simulation has also been performed with a field of view limited to a circle of $500 \mathrm{~km}$ radius high spatial resolution mode). The results given in Figure 12 show that, in this case, the lightning activity cannot be observed every day. Moreover, due to the size of the field of view, the total detection period is limited to 3 minutes which is not enough to characterise the life cycle of the convective system.

In order to get a statistical approach of the detection efficiency in various conditions, a daily average of the flash rate (full black circles) is given on Figure 13 for a field of view up to the limb and on Figure 14 for a reduced field of view $(1000 \mathrm{~km}$ diameter). In both cases, this parameter is widely scattered but its average cumulated value converges in less than 20 days (Figure 13) to the theoretical value $(0.98 \mathrm{flash} / \mathrm{s})$. On the contrary, it is shown on Figure 14 that the use of a restricted field of view results in a bias of $26 \%$ on the average cumulated values : in this case, the mean flash rate tends to $0.74 \mathrm{flash} / \mathrm{s}$ after 100 days. As a conclusion, the large field of view enables to reach an accurate estimation of monthly variations of lightning activity of a convective system.
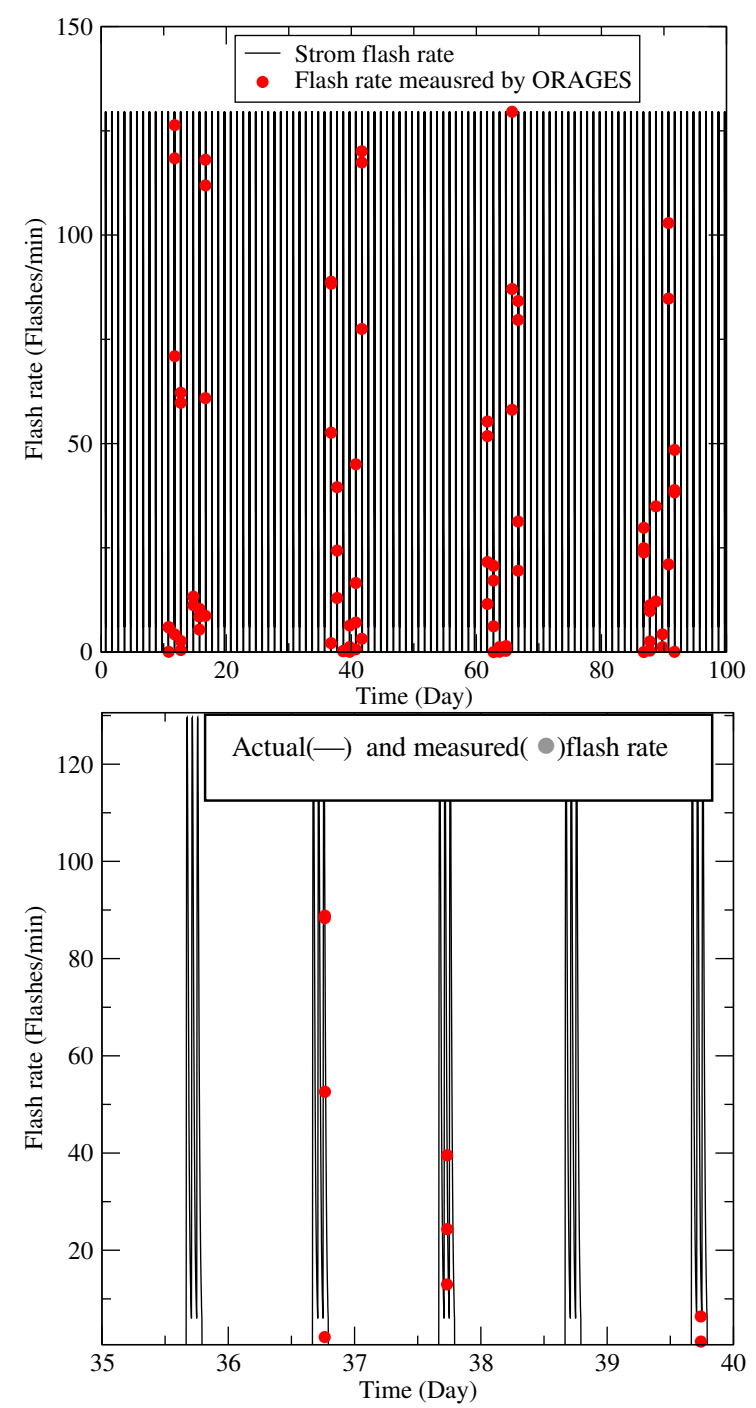

Figure 12 : Flash rate measured by ORAGES for a typical storm at $0^{\circ}$ of latitude and $0^{\circ}$ of longitude with a field of view of $1000 \mathrm{~km}$ of diameter.

\section{Case of single cell storms}

This analysis has been extended to the case of a single cell thunderstorm (size : $10 \mathrm{kmx} 10 \mathrm{~km}$ ) : Figure 15 and Figure 16 show the probability of detection of such a storm developing each day at the same location, as a function its duration, its latitude and of the size of the field of view. The probability has been computed over 100 days of observation. For a large field of view, the probability of detection is higher than $50 \%$, for a storm duration of 1 hour. The instrument performances and selected mission parameters then lead to a good statistical analysis of various lightning activity, from large mesoscale systems down to small size, single cell storms. 


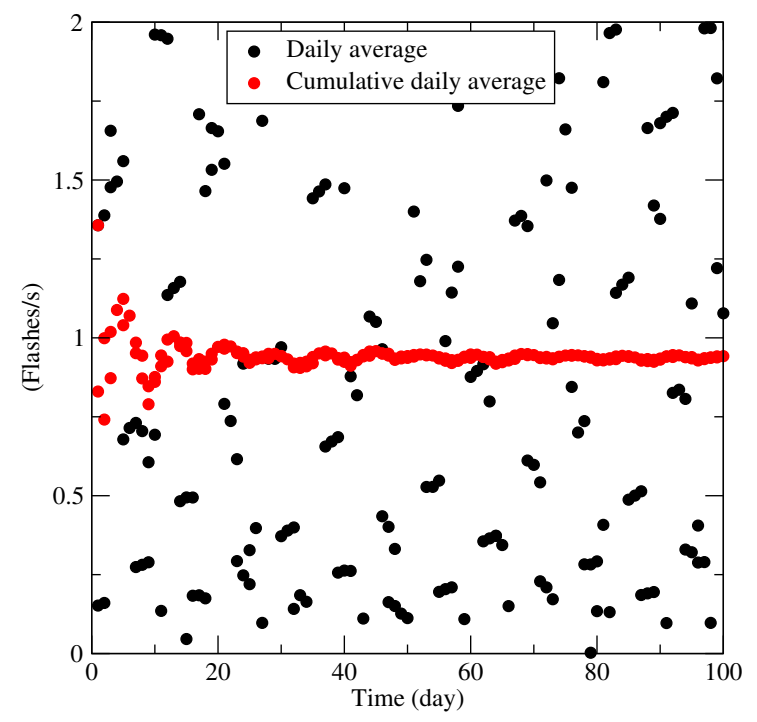

Figure 13 : Variation of the mean flash rate as a function of the day (daily average) and the number of days taking into account in the average. Field of view up to the limb. Storm center at $0^{\circ}$ of latitude and $0^{\circ}$ of longitude

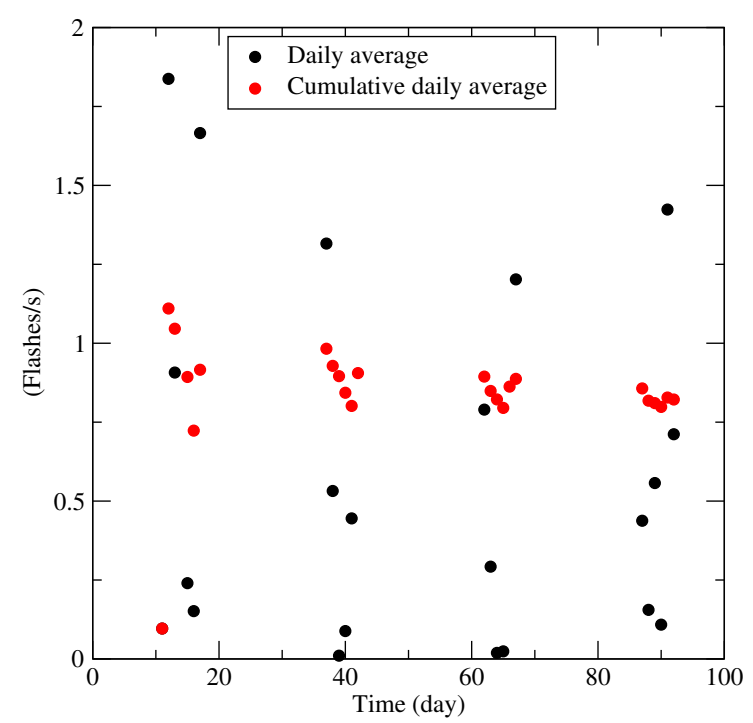

Figure 14 : Variation of the mean flash rate as a function of the day (daily average) and the number of days taking into account in the average. Field of view of $1000 \mathrm{~km}$ of diameter. Storm center at $0^{\circ}$ of latitude and $0^{\circ}$ of longitude

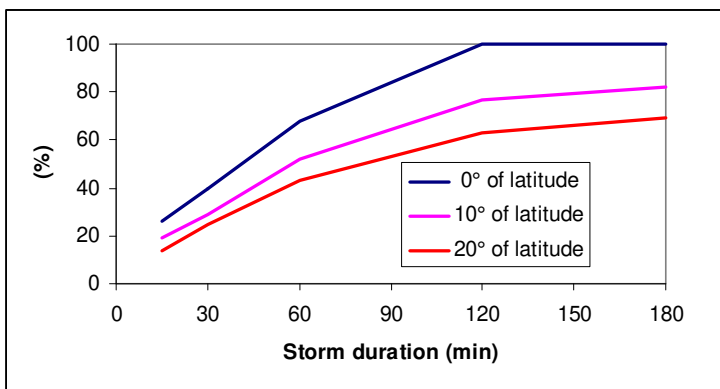

Figure 15 : Variation of the probability of detection of 1 storm cell as a function of its development latitude and its duration for a field of view up to the limb.

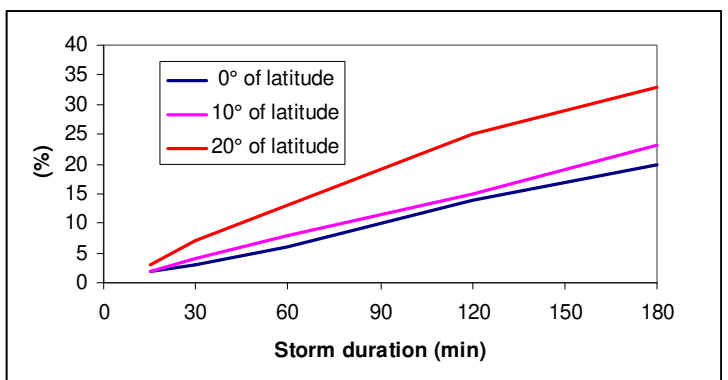

Figure 16 : Variation of the probability of detection of 1 storm cell as a function of its development latitude and its duration for a field of view

\section{CONCLUSION}

The ORAGES instrument enable to detect all kind of lightning flashes within tropical convective systems; the ORAGES data may be combined with ground based and spaceborne meteorological products to investigate the processes involved in the evolution of convective systems. These results will contribute to understand the atmospheric water cycle leading to precipitation at the earth's surface which strongly modulates the seasonal and geographical variations of the climate. The ORAGES payload is very well adapted to follow with a good probability of detection the life cycle of different kinds of convective systems.

\section{REFERENCES}

Lhermitte, R., and E.R. Williams, 1983 : Rev. Geophys., 21, 984-992

Saunders, C.P.R., W.D. Keith et R.P. Mitzeva, 1991 : J. Geophys. Res. , 96, 11007-11017

Chèze, J.L., and H. Sauvageot, 1997 : J. Geophys. Res. , 102, 1707

Toracinta, E.R., et E.J. Zipser, 2001 : J. Appl. Meteor., 40, 983-1002.

Toracinta, E.R., D. Cecil, E.J. Zipser et S.W. Nesbitt, 2002 : Mon. Wea. Rev., 130, 802-824 Price, C., 1993 : Geophys. Res. Lett., 20, 13631366 ; Williams, E.R., 1994 : Mon. Wea. Rev., 122, 1917-1929

Price C, 2000 : Nature, 206, pp 290-293

Massey, R.S., and D.N. Holden, 1995, Radio Sci., 30 (5), 1645-1659.

Massey, R.S., S.O. Knox, R.C. Franz, D.N. Holden, and C.T. Rhodes, 1998, Radio Sci., 33 (6), 17391753. 